\title{
Topographic archaeology revisited: regional archaeological structure in the southern Wimmera, Victoria, Australia
}

\author{
Caroline Bird ${ }^{1}$ and James W. Rhoads ${ }^{2}$ \\ ${ }^{1}$ PO Box 217, Glen Forrest, Western Australia 6071, Australia. Email: birho@optusnet.com.au \\ ${ }^{2}$ Research Section, Principal Registry, National Native Title Tribunal, \\ GPO Box 9973 Perth, Western Australia 6848, Australia. Email: Jim.Rhoads@nntt.gov.au
}

\begin{abstract}
In this paper we explore the relationship between regional distributions of surface archaeological remains and long term landscape features in the semi-arid southern Wimmera region of Victoria. We conclude that both point and linear water sources concentrate settlement at particular points in the landscape ('sites'). However, at a regional level, the nature and distribution of water resources also influences the character of the background scatter.
\end{abstract}

KEYWORDS: surface artefact scatters, regional analysis, water

\section{INTRODUCTION}

In 1977, Sylvia Hallam argued for a new line of attack for Australian archaeology that she termed 'topographic archaeology'. This approach drew upon the long British tradition of landscape studies in both archaeology and geography. It focussed on detailed regional investigation of long term dynamic socio-demographic, economic and cognitive relationships between human populations and ecosystems. Her own study of the Perth metropolitan area, begun in the early 1970s, exemplified the two key strands of her approach. The first was a meticulous investigation of the structure of the regional archaeological record through detailed site recording and analysis of archaeological site distribution, with careful correction for factors such as visibility and survey coverage. The second strand was the establishment of an 'ethnographic baseline', through the detailed investigation of historical sources.

Sylvia was a passionate advocate of detailed regional studies which she explicitly contrasted with continent-wide models. Rather, she focused on understanding dynamic relations between human populations and the ecosystem of which they are an active component, comprising sociodemographic, economic and cognitive aspects of the 'linkage of landed groups and peopled landscape' (1977: 175). This approach strongly influenced the archaeological work done by many of her students (e.g. Anderson 1984; Bird 1985; Ferguson 1985; Brown 1987; Schwede 1990; Smith 1993). In Sylvia's own work in the Perth Archaeological Survey Transect, with meticulous field recording enriched by comprehensive analysis of the available historical sources, she showed long term continuity in how occupation of the Swan Coastal Plain was structured around wetlands rather than the littoral (Hallam 1987). This was an example of how continent-wide models (in this case, coastal colonisation) could be tested at the local and regional scale through detailed analysis of the structure of the archaeological record.

The Perth Archaeological Survey Transect was a tour de force of recording and analysing thousands of surface artefacts. The pace of development in the Perth metropolitan area since the 1970s means that the database generated can never now be replicated. But it was deeply unfashionable at the time. Most Australian archaeologists then gave priority to excavation of deep occupation sites with long sequences, rather than tackling the challenges posed by surface scatters. Its long-term approach also differed from short-term surveys aimed at addressing specific questions of land use, especially those associated with development (McBryde 1986: 19-20).

The study of surface artefacts at a regional scale - those 'horrid little bits of stone' (Hallam 1977: 169) - remains largely unfashionable in 
Australian archaeology. While it is the primary concern of much archaeology in the public sector, it has received relatively little research effort. The problems of establishing chronology and the sheer scale of time and effort involved in field recording required to produce meaningful results have largely deterred Australian archaeologists from taking up Sylvia's challenge. This is, however, not the case in other archaeological regions (e.g. Haselgrove et al. 1985; Shennan 1985; Ebert 1992; Rossignol and Wandsnider 1992) and, in Australia, the Western New South Wales Archaeological Project has demonstrated the value of investigating the distribution of surface artefacts and features within their geomorphological context (e.g. Holdaway et al. 1998; Doelman et al. 2001; Doelman 2005; Holdaway et al. 2005).

Most surface surveys in Australia are conducted in the context of management of cultural heritage threatened by development. This implies constraints of time and resources, and militates against the development of robust sampling strategies. The usefulness of the site concept has been widely questioned in archaeology, particularly for hunter-gatherer societies (e.g. Thomas 1975; Foley 1981; Dunnell and Dancey 1983; Ebert 1992). It is widely observed that many landscapes have a continuous 'background scatter' of artefacts. Nevertheless, the practical requirement of state heritage agencies in Australia that the 'site' is the main unit of recording for registration purposes, coupled with the constraints of the development agenda, mean that it is commonly difficult to examine alternative ways of recording and analysing surface artefacts, including non-site approaches. Consequently, in the 21st century, it is still the case that most field archaeology in Australia concentrates on recording and conserving ubiquitous surface scatters of stone artefacts. Hence they remain poorly understood and have generally contributed little to our understanding of Indigenous archaeology (Holdaway et al. 1998: 1). One might go so far as to say that surface scatters are understood more by what archaeologists think they mean, than by what practitioners can demonstrate through the application of archaeological methods.

This paper explores regional archaeological structure in the Wimmera region of western Victoria. The data come from a major survey conducted in 1990 as part of the Victoria Archaeological Survey's State-wide Aboriginal Site Survey program. This program aimed to undertake baseline survey and assessment of cultural resources in specific areas and to provide training for local Aboriginal community members in site survey and management (Rhoads 1992; Rhoads and Bird 2000: 1). The south-west Wimmera Project also

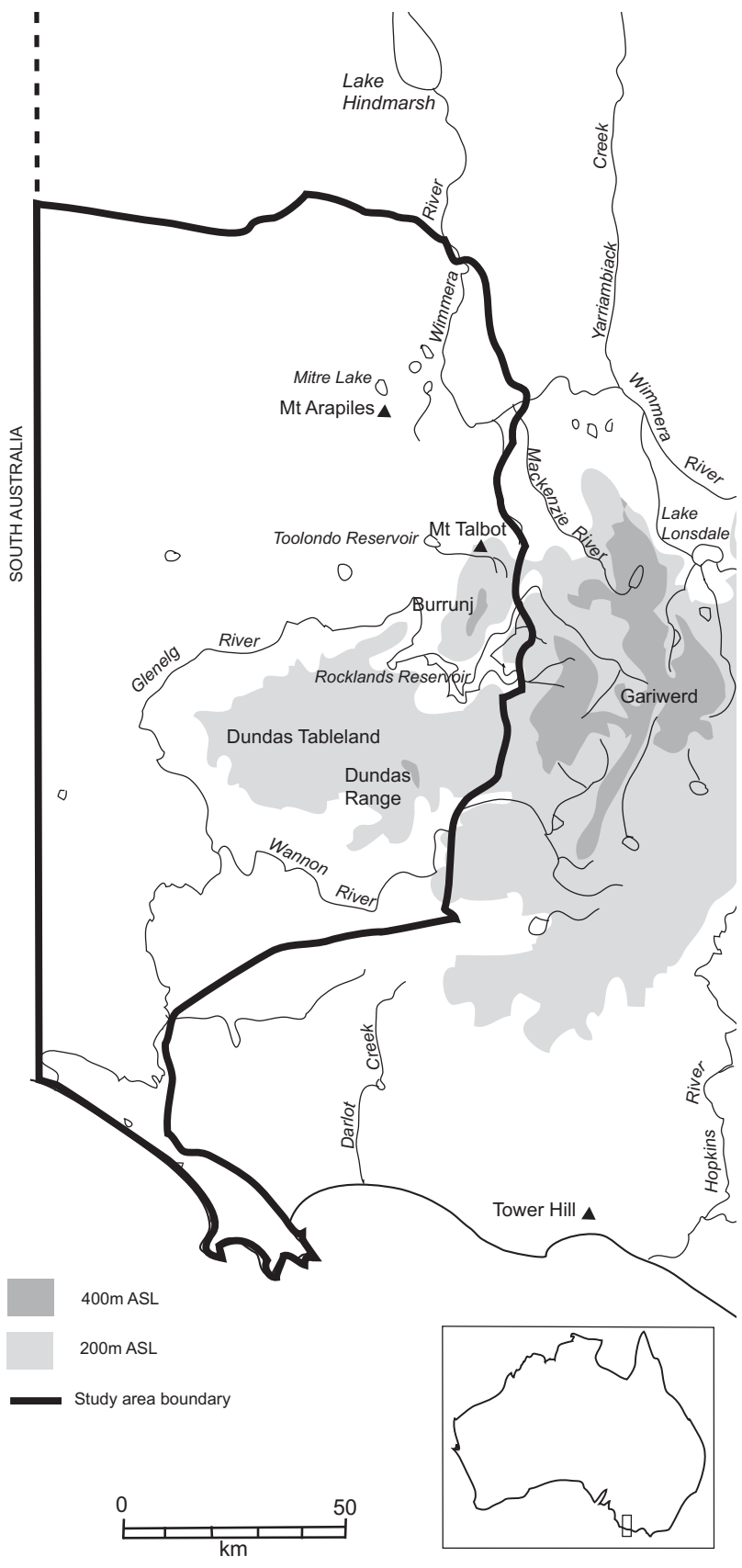

FIGURE 1

South-west Victoria, showing the study area.

attempted to explore how alternative approaches, including non-site data, could be effectively integrated into a regional-scale survey program. The robust fieldwork strategy employed sought to balance the resource limitations common to most cultural heritage management archaeology with systematic sampling at a regional scale.

\section{BACKGROUND}

The south-west Wimmera Project was conducted among the sand plains west and north of the Glenelg River (Figure 1). The region has little permanent surface water and the climate is 
TABLE 1 Summary of environment types represented in the study area and key to abbreviations used in the text.

\section{CODE* DESCRIPTION}

\begin{tabular}{ll}
\hline A & Alluvial plain with red gum \\
B & $\begin{array}{l}\text { Sand plain with brown stringybark } \\
\text { woodland }\end{array}$ \\
W & $\begin{array}{l}\text { Sandy clay plain with gum/box/ } \\
\text { buloke savannah woodland }\end{array}$ \\
M & $\begin{array}{l}\text { Alluvial plain with mosaic of red gum } \\
\text { forest and gum/box/buloke savannah } \\
\text { woodland }\end{array}$ \\
L & Lake shore with red gum \\
D & Source bordering dune \\
\hline
\end{tabular}

* These codes are used throughout this paper

generally dry with winter rainfall. Most of the landscape seen today formed in ancient times and consists of hardened sand ridges with chains of lakes and swamps in the low areas between them (Bowler and Magee 1978; Land Conservation Council 1979, 1985; Jenkin et al. 1988). The study area also included the Wimmera River and rugged outliers of Gariwerd (the Grampians).

The region has three main vegetation formations (Land Conservation Council 1985). The dominant vegetation community is open woodland of gum, box and buloke with a grassy understorey occurring mainly on clay plains. Brown stringybark woodland is found on poorer sandy soils and has a scrubby rather than a grassy understorey. This is the least productive environment. River red gum occurs as open woodland and open forest and is particularly associated with reliable supplies of fresh water, such as lakes, swamps and watercourses, and in seasonally flooded areas. A mosaic of red gum forest and mixed open woodland is also found in the study area. Historical records suggest that wetlands, with their rich food resources, were particularly important in the traditional Aboriginal settlement pattern. Table 1 summarises the natural environment in terms of vegetation alliances, soils and landforms.

The south-west Wimmera itself is poor in stone and the types preferred for tool making are scarce. Important sources of stone are Mt Arapiles, Mt Talbot and the Black Range. Quartzite quarries are known in all three areas (Edmonds 1992; Bird 1995; Long 1995a, 1995b; Webb 1995; Bird and Frankel 1998). The Mallee is a potential source of silcrete and quarries of this material have been recorded in the region (Ross 1986: 28; Webb 1995: $37-38,41)$. Chert and flint can be obtained from south-eastern South Australia and coastal Victoria (Scott-Virtue 1982). Volcanic rock to the east and west of Gariwerd, and the Glenelg River as well as Gariwerd itself, are all possible sources of quartz, quartzite, chert, volcanic glass, hornfels and rhyolite (Cayley and Taylor 1997). To the east of Gariwerd, the greenstones of the Mt Stavely Belt are known to have been quarried in a number of localities and hatchets made from this material were widely traded (Coutts et al. 1976: 9; McBryde 1978).

Traditionally, the area was divided between two Aboriginal groups - the Wergaia to the north and the Jardwadjali to the south. Both groups spoke related dialects that belonged to the Kulin group of languages spoken throughout central and inland western Victoria (Clark 1990, 1998). Historical sources suggest that the permanent population was probably quite small. This idea, however, must be treated with some caution because of the terrible impact of European settlement on the local population. The Wimmera Aborigines strongly resisted European settlers and Mt Arapiles seems to have been an important centre of resistance. In the end, however, guns won out against the Aboriginal people, who were devastated by introduced diseases. Ebenezer Mission, near Lake Hindmarsh, became the main reserve for the Wimmera. It was finally closed in 1904. Today, the Goolum Goolum Aboriginal Co-operative in Horsham represents the Wimmera Aboriginal community.

Prior to the survey, little archaeological work had been carried out in the study area. Most of the 35 known sites at the time of the south-west Wimmera Project were chance finds. These included burials, scarred trees, mounds and the Toolondo fish trap complex. Seven of the recorded sites were burials located in sand bodies, such as lunettes or source bordering dunes. The four mounds recorded all occur on poorly drained land associated with a complex of lakes and swamps within $10 \mathrm{~km}$ of Toolondo reservoir.

Systematic field archaeological work in the study area was largely limited to Lourandos' study (1980; cf. Massola 1962) of the Toolondo fish trap, recording of rock art in Burrunj (the Black Range) (Gunn 1987), and excavations at the MK1 mound (Coutts and Witter 1977), Mugadgadjin (formerly known as Black Range 2) (Coutts and Lorblanchet 1982; Bird et al. 1998; Bird and Frankel 2005) and Mt Talbot 1 (Bird 1995). A useful review of the archaeological and historical information for the Horsham region of what was then the Department of Conservation, Forests and Lands (now Department of Sustainability and Environment) was produced in 1990. The study 
area overlaps substantially with the north-west and south-west sectors of the region (Bird 1990). This review also includes a general regional model of site location and predictive statements about site location in specific areas, such as the Little Desert and the Southern Wimmera Plains. Since the project was completed substantial regional surveys have focussed on the Wimmera River itself (Russell 1992; Archaeological Consulting Services 1997; Edmonds 1998) and the Yarriambiack Creek, to the north-east (Kamminga and Grist 2000).

To the east of the study area, Gariwerd has certainly been occupied for at least 22,000 years (Bird et al. 1998; Bird and Frankel 2005). Burrunj, at the eastern edge of the study area, has a number of art sites and quarries. Evidence of occupation in the site of Mugadgadjin goes back about 4,500 years. Mt Talbot and Mt Arapiles also have evidence of art, rockshelter occupation and quarries. The site of Mt Talbot 1 was first occupied about 5,000 years ago. Radiocarbon dates from Toolondo and the mound site MK1 are less than 1,000 years old (Coutts and Witter 1977; Lourandos 1980; Coutts and Lorblanchet 1982; Edmonds 1992; Long 1995a, 1995b; Bird 1995; Bird et al. 1998; Bird and Frankel 2005).

\section{SURVEY METHODS}

Large-scale regional surveys are an important tool for heritage managers developing predictive models of site location. Traditionally, such surveys tend to use land systems as a basis for sampling. These are commonly derived from a combination of soils, vegetation and geomorphology and relate primarily to contemporary land use potential (e.g. Hughes and Sullivan 1984; Pearson and Sullivan 1995: 100). In practice, many archaeological surveys conducted as part of Environmental Impact Assessment processes are constrained by client requirements. In the absence of systematic regional surveys and a broader understanding of the structure of the archaeological record of an area, it is difficult, if not impossible, to assess significance, especially where visibility and access are key factors in determining what areas are actually inspected.

With the aim of characterising regional archaeological structure and providing a sound predictive basis for future assessments, the SouthWest Wimmera Project took a rather different approach. The entire study area was divided into 10 x $10 \mathrm{~km}$ sample units. Key long-term mapped features of the landscape, such as relief, and the nature and type of water source, were recorded for each one kilometre square in each sample unit. These attributes were selected because they are stable over a long period of time and they vary in direct relationship to one another over time. Statistical techniques (multivariate analysis and clustering) were then used to identify five landscape types (Table 2). These landscape types formed the basis of a random stratified sampling approach to define areas for survey.

This approach characterises the landscape in terms of increasing relief and increasing reliability and quantity of surface water in strata 1-4.

TABLE 2 Individual sampling strata, characterised in terms of landscape features and their representation in the study area.

\begin{tabular}{|c|c|c|c|}
\hline STRATUM & $\begin{array}{l}\text { NUMBER OF } \\
\text { SOUARES }\end{array}$ & DESCRIPTION & $\begin{array}{l}\text { SURVEYED } \\
\text { SAMPLE SQUARE }\end{array}$ \\
\hline 1 & 23 & Flat, relatively waterless plain & $\begin{array}{l}\text { 1A Oakdale } \\
\text { 1B Little Desert }\end{array}$ \\
\hline 2 & 17 & $\begin{array}{l}\text { Mostly flat plain with seasonal swamps and } \\
\text { ephemeral waterways }\end{array}$ & $\begin{array}{l}\text { 2A Carpolac } \\
\text { 2B Mundarra }\end{array}$ \\
\hline 3 & 16 & $\begin{array}{l}\text { Rolling terrain with numerous seasonal } \\
\text { waterways }\end{array}$ & $\begin{array}{l}\text { 3A Lower Norton } \\
\text { 3B Mosquito Creek }\end{array}$ \\
\hline 4 & 18 & Rolling landscape with lakes & $\begin{array}{l}\text { 4A Miga Lake } \\
\text { 4B Clear Lake }\end{array}$ \\
\hline 5 & 25 & Outliers - mainly with rugged terrain or rivers & $\begin{array}{l}\text { 5A Natimuk } \\
\text { 5B Vectis }\end{array}$ \\
\hline
\end{tabular}




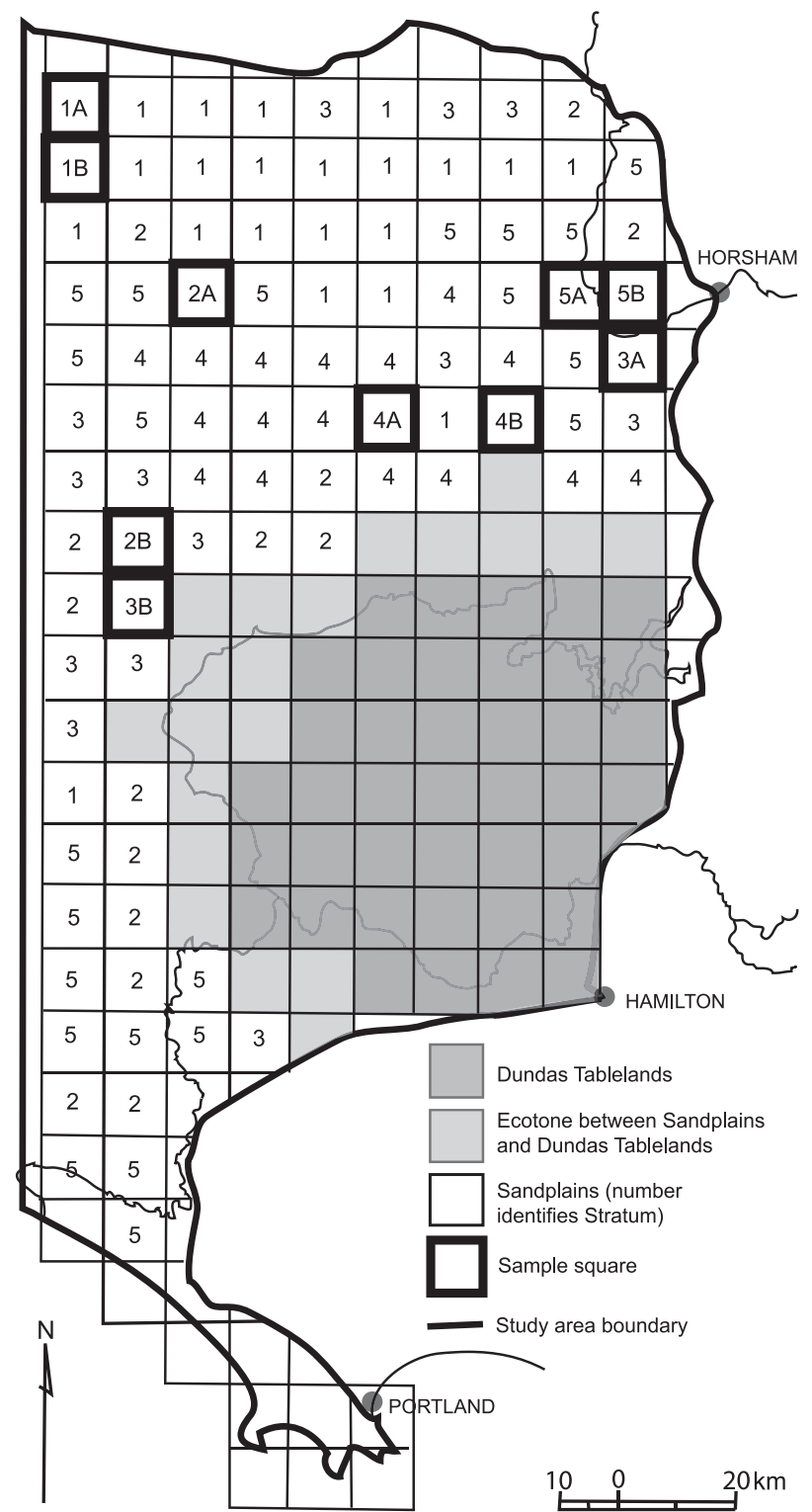

FIGURE 2

The study area, showing distribution of sampling strata and survey sample squares.

Stratum 5 groups those sample squares that can be considered as anomalous at a regional scale. It includes unusual or unique landscape features, such as the Wimmera River or rocky outcrops like Mt Arapiles.

Two squares were chosen at random from each stratum prior to commencing fieldwork. Extra squares were also chosen at random in case the original squares were not suitable for investigation due to poor ground surface visibility. For the purposes of the analysis that follows, the environment occurring in each sample unit is also characterised with reference to associated vegetation alliances. The distribution of these has been recorded for each of the sample units (Table 3). The sampling strategy and field survey methods are discussed more fully elsewhere (Rhoads 1992;
Rhoads and Bird 2000).

\section{SURVEY RESULTS}

Ten sample units, about $10 \%$ of the whole region, were actually surveyed (Figure 2), as a result of the sampling strategy and field assessment outlined above. Limitations of visibility and access meant that the effective area surveyed was, of course, rather smaller than this. Table 3 shows the effective areas surveyed for each sample square and stratum. These range from about 1.4 to $3.2 \mathrm{~km}^{2}$. Under ideal conditions, comparable proportions of each stratum would have been surveyed. However, this was difficult to achieve. If we consider $2 \mathrm{~km}^{3}$ (i.e. a $1 \%$ sample) as an acceptable threshold for each stratum, neither stratum 1 nor stratum 4 has been investigated to a level comparable with the others. Nevertheless, only Little Desert (Square 1B) is seriously under investigated. This is because it was entirely vegetated with dense stringybark scrub and visibility was exceptionally low.

More problematic is whether the area actually surveyed can be regarded as broadly comparable to the sample unit as a whole. Figure 3 compares the actual area of each environment type within a square with its representation in the survey. For six squares - Oakdale (1A), Little Desert (1B), Carpolac $(2 \mathrm{~A})$, Lower Norton (3A), Natimuk (5A) and Vectis (5B) - the environment types represented in the survey are broadly equivalent to their actual occurrence. In general, the presence of lakes and watercourses (often on public land, easily accessible for investigation) seems to have skewed the surveyed sample and clay plains with red gum forest, lake shores and source bordering dunes are somewhat over-represented. The main exceptions here are the over-representation of stringybark woodland in the Carpolac (2A) sample and mixed savannah woodland in Clear Lake (4B).

In summary, the methodology adopted in this analysis characterised the landscape at a regional scale in terms of topography, and water source and availability in order to derive a sampling strategy. Fieldwork was then organised to minimise bias due to variations in access and visibility. Although only a relatively small percentage of the area was actually inspected, the resulting archaeological sample is robust and can be considered reasonably representative of the region.

\section{SURVEY FINDINGS}

A total of 428 sites was recorded in the course of the survey. These included 231 scarred trees (see Rhoads 1992), 60 surface artefact scatters and 137 isolated finds. No mounds were discovered during the survey (see Rhoads and Bird 2000).

All artefact occurrences (surface scatters and 


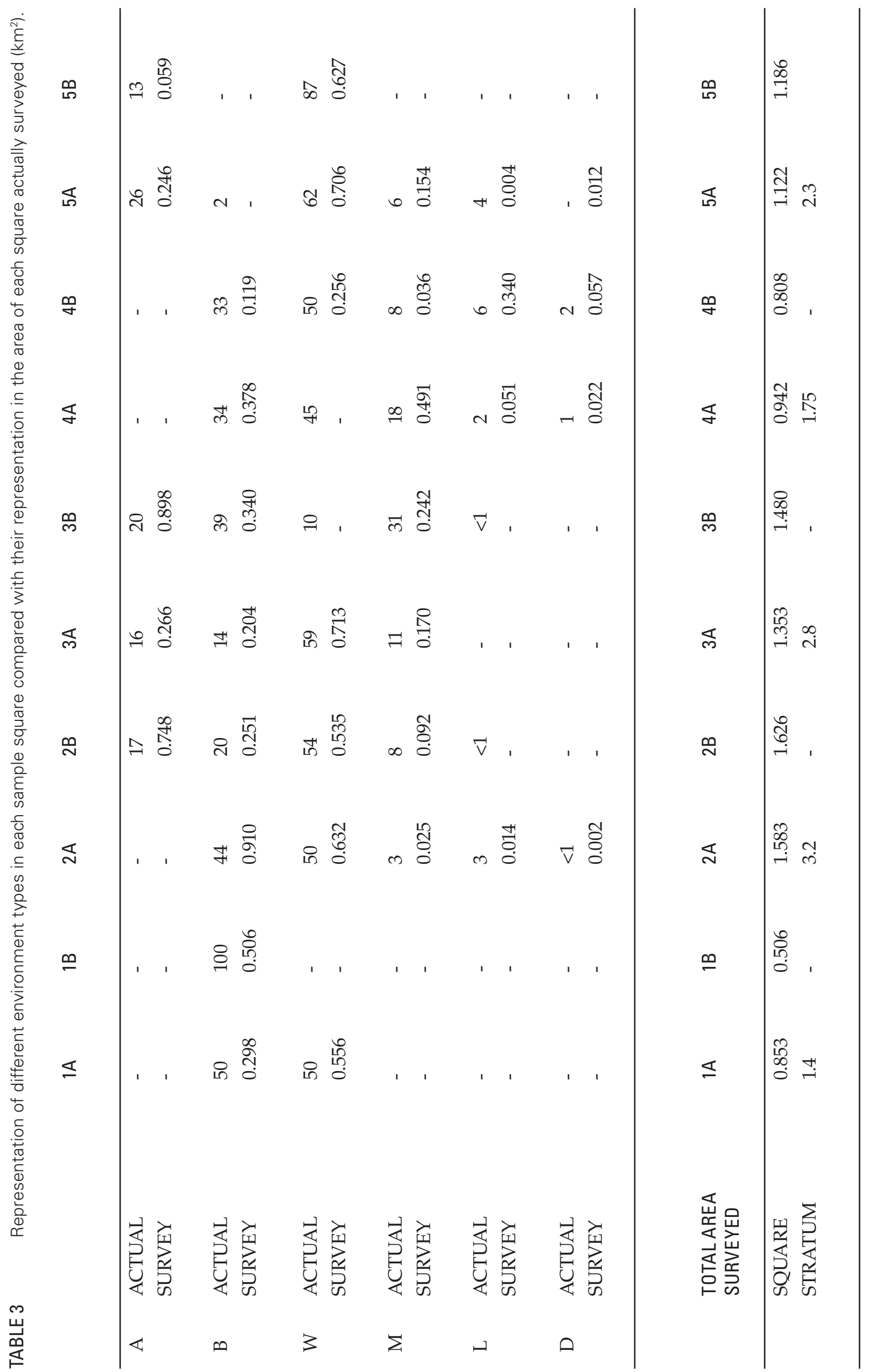


1A Oakdale

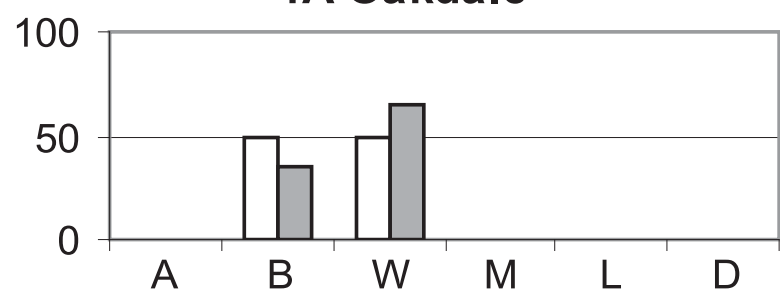

2A Carpolac

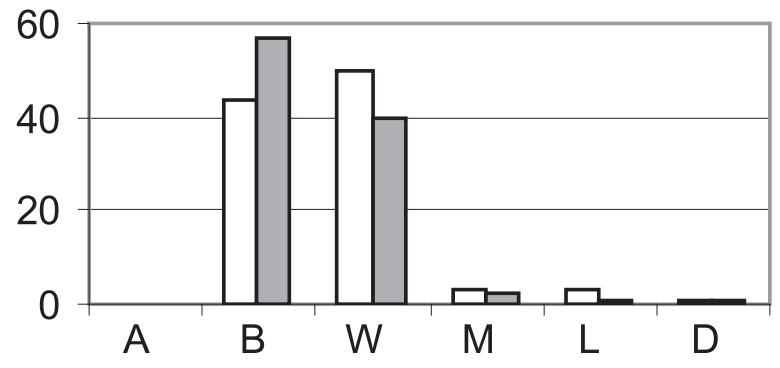

3A Lower Norton

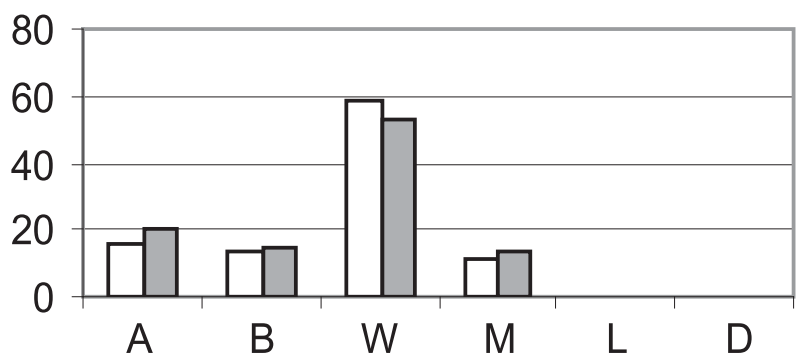

4A Miga Lake

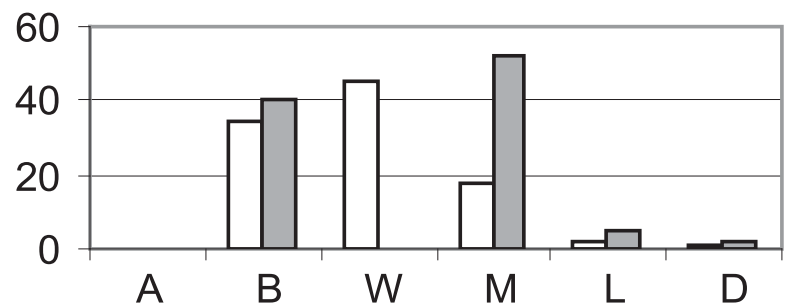

5A Natimuk

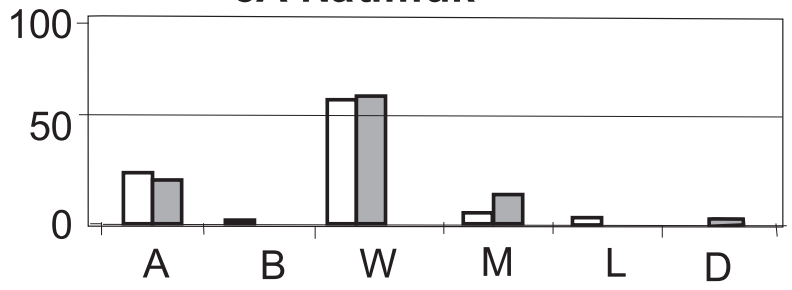

1B Little Desert

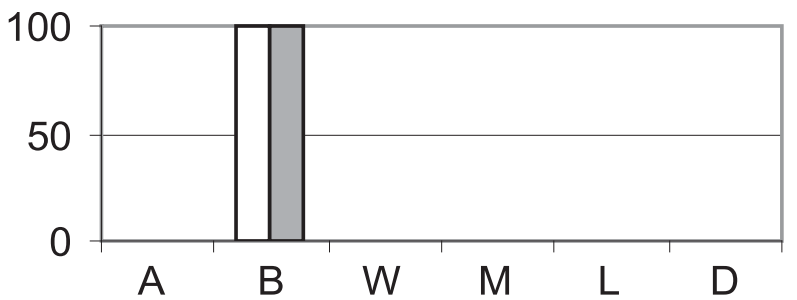

2B Mundarra

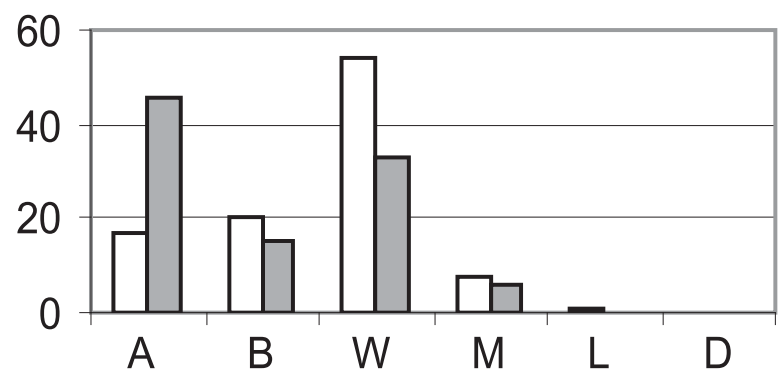

3B Mosquito Creek

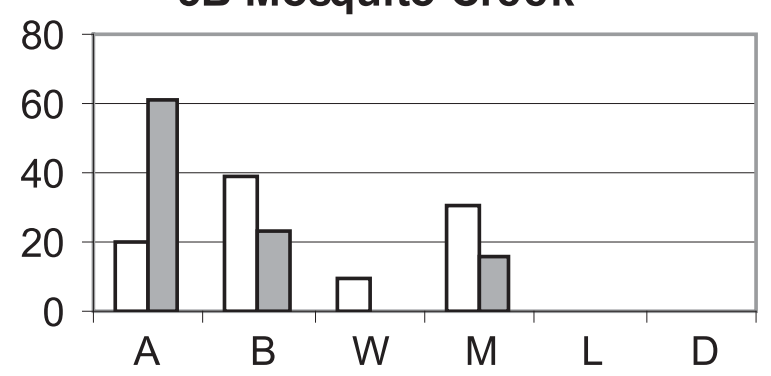

4B Clear Lake

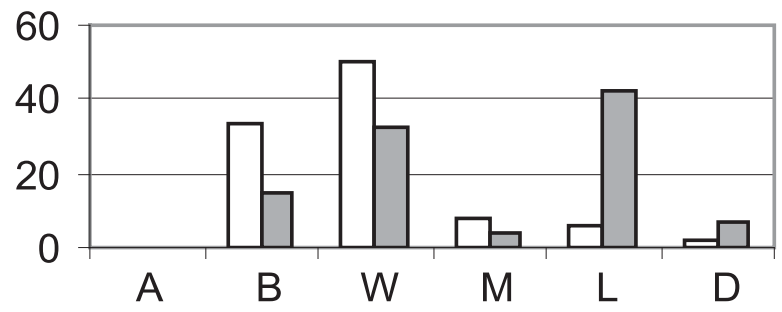

5B Vectis

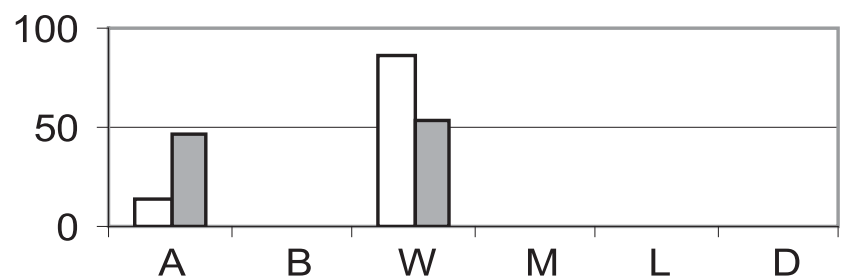

$\square$ Actual $\quad \square$ Surveyed 
isolated artefacts) were divided into four classes:

- $\quad$ very small (1-10 artefacts),

- $\quad$ small (11-100 artefacts),

- medium (101-500 artefacts),

- $\quad$ large (> 500).

Although this classification seems to be a continuum, in practice, only two sites classified as 'small' had more than 50 artefacts, while all medium sites ranged between about 100 and 250 artefacts. Large sites stood out because of the quantity and density of artefacts. Most artefact occurrences were small or very small, comprising 10 or fewer artefacts, while large and medium occurrences were rare (Table 4). In fact, large and medium sites were entirely absent from stratum 3 (Lower Norton and Mosquito Creek) and from Vectis (5B), Carpolac (2A) and Little Desert (1B) (Table 4). Sample size varies considerably between sample squares. Little Desert (1B) has such a small sample that it must be excluded from most of the analysis, while only small samples could be recorded from Carpolac (2A), Mosquito Creek (3B) and Vectis (5B).

In summary, small and very small artefact occurrences represent a regional background scatter, while medium and large sites are more likely to indicate locations which are foci of more concentrated settlement activity. Scarred trees are a form of off-site data, associated with specific resource procurement activities.

\section{REGIONAL DISTRIBUTION OF ARTEFACT OCCURRENCES AND SCARRED TREES}

Table 5 shows the overall actual distribution of artefact sites with respect to stratum and environment. The absolute number of occurrences clearly increases from Stratum 1 to Stratum 4. This aligns well with the interpretation that strata 1-4 represent increasing reliability and type of water sources. The two sample units surveyed in Stratum 5 are distinguished by the presence of the Wimmera River and are in other respects broadly similar to stratum 3, which is characterised by seasonal waterways. The distribution of artefact occurrences in relation to different environment types confirms that they are strongly associated with lakeshores and dunes. Sites are also more common than would be expected in the alluvial plains carrying a mosaic of red gum forest and mixed savannah woodland $(\mathrm{M})$, that is, the most diverse environmental category.

The distribution of scarred trees differs from the distribution of artefact occurrences (Table 5). Unsurprisingly, scarred trees are distributed in environments where the tree species overwhelmingly preferred for procurement of bark (i.e. grey box and red gum) are found. Like artefact occurrences, scarred trees are more common than might be expected in the mosaic of red gum forest and mixed savannah woodland. Scarred trees are absent in the sand plains, which mainly carry stringybark woodlands. However, unlike artefact occurrences, most scarred trees occur in strata 3 and 5. This patterning may be related to the survival of trees along river and streamside reserves; however, mature trees also occur in road reserves throughout the study area

TABLE 4 Distribution of types of artefact occurrences by sample squares.

\begin{tabular}{lllllll} 
& & LARGE & MEDIUM & SMALL & VERY SMALL & TOTAL \\
\hline 1A & Oakdale & 2 & 1 & 1 & 13 & 17 \\
1B & Little Desert & 0 & 0 & 0 & 3 & 3 \\
2A & Carpolac & 0 & 0 & 1 & 10 & 11 \\
2B & Mundarra & 1 & 0 & 0 & 19 & 20 \\
3A & Lower Norton & 0 & 0 & 8 & 20 & 28 \\
3B & Mosquito Creek & 0 & 0 & 0 & 11 & 11 \\
4A & Miga Lake & 0 & 2 & 3 & 33 & 38 \\
4B & Clear Lake & 3 & 1 & 4 & 21 & 29 \\
5A & Natimuk & 0 & 2 & 13 & 17 & 32 \\
5B & Vectis & 0 & 0 & 1 & 7 & 8 \\
\hline & TOTAL & 6 & 16 & 31 & 154 & 197
\end{tabular}


TABLE 5 Observed and expected distribution of artefact occurrences $(N=197)$ and scarred trees $(N=231)$ with respect to environment type $(A)$ and stratum $(B)$.

\begin{tabular}{lllll} 
A & ARTEFACT OCCURRENCES & & SCARRED TREES \\
ENVIRONMENT & OBSERVED & EXPECTED & OBSERVED & EXPECTED \\
\hline A & 32 & 47 & 49 & 55 \\
B & 32 & 51 & 7 & 60 \\
W & 37 & 69 & 16 & 12 \\
M & 35 & 20 & 73 & 23 \\
L & 50 & 8 & 86 & 81 \\
D & 11 & 2 & - & - \\
\hline
\end{tabular}

Chi-square $=298.96, \mathrm{df}=5, P<0.01$

Chi-square $=157.81, \mathrm{df}=4, P<0.01$

\begin{tabular}{lllll} 
B & ARTEFACT OCCURRENCES & \multicolumn{3}{l}{ SCARRED TREES } \\
STRATUM & OBSERVED & EXPECTED & OBSERVED & EXPECTED \\
\hline 1 & 20 & 39.4 & 40 & 46.2 \\
2 & 31 & 39.4 & 19 & 46.2 \\
3 & 39 & 39.4 & 94 & 46.2 \\
4 & 67 & 39.4 & 18 & 46.2 \\
5 & 40 & 39.4 & 60 & 46.2 \\
\hline
\end{tabular}

Chi-square $=30.69, \mathrm{df}=4, P<0.01$

and these locations were rigorously investigated for scarring. Therefore, the distribution of scarred trees may not necessarily be the product of differential preservation (Rhoads 1992).

The relative density of artefacts from small and very small sites provides a general measure of the background scatter at a regional level. Table 6 indicates that regional artefact density estimated from these occurrences increases from stratum 1 to stratum 4, and stratum 5 broadly resembles stratum 3 (cf. Table 5). Thus, at a landscape scale, variation in the regional density of artefacts represented by the background scatter alone reflects changing quantity and reliability of water sources.

\section{CHARACTERISTICS OF SURFACE ARTEFACT OCCURRENCES}

Artefact assemblages are generally uniform throughout the whole study area. At a regional level, most artefacts were quartz with the proportion of chert ranging from $45 \%$ to $4 \%$. Silcrete and quartzite occurred in very small quantities. Retouched tools were uncommon. About half of the retouched tools were backed pieces, including both bondi points and geometric microliths. The rest were retouched flakes. Most cores were bipolar. With the exception of raw material composition, the assemblages from different parts of the study area were generally similar in composition and characteristics (Rhoads and Bird 2000).

TABLE 6 Regional artefact density, estimated from small and very small artefact occurrences.

\begin{tabular}{lll} 
STRATUM & $\begin{array}{l}\text { TOTAL } \\
\text { ARTEFACTS }\end{array}$ & $\begin{array}{l}\text { NUMBER OF } \\
\text { ARTEFACTS KM }\end{array}$ \\
\hline 1 & 20 & 15 \\
2 & 57 & 18 \\
3 & 113 & 40 \\
4 & 162 & 93 \\
5 & 107 & 46 \\
\hline
\end{tabular}




\section{All artefact occurrences}

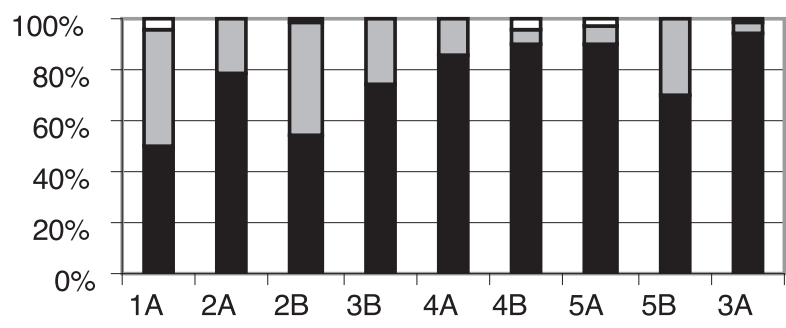

Small and very small artefact occurrences

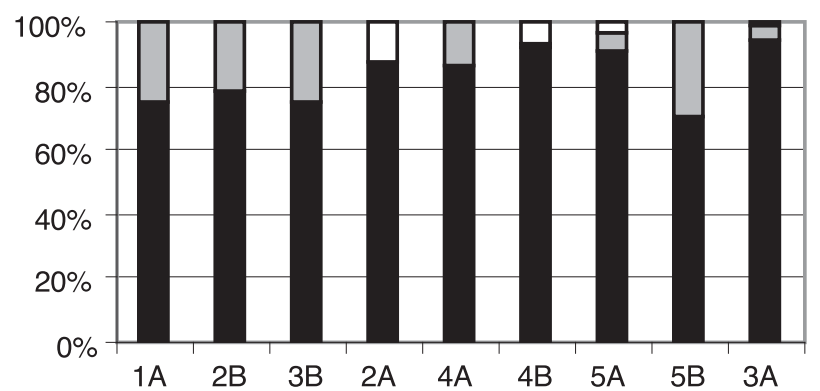

Large and medium artefact occurrences

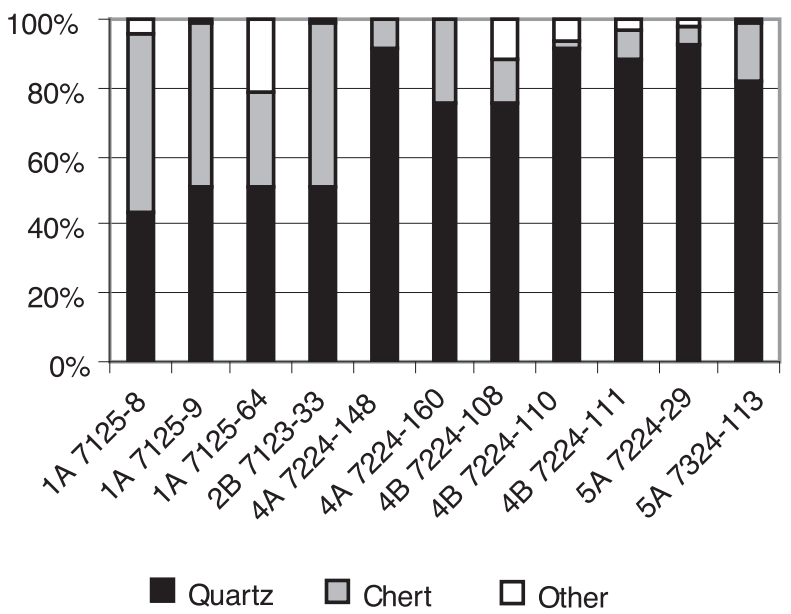

FIGURE $4 \quad$ Variation in raw material composition from west to east.

To examine regional trends, the summary assemblage data from all individual artefact occurrences within a sample unit were amalgamated. Ordering sample squares from west to east suggests a regional trend from quartz dominated assemblages in the east to higher proportions of chert in the west (Figure 4). Vectis is the most obvious anomaly, but this can probably be explained by the small number of sites comprising this sample. Small sample size may also account for the relatively high proportions of quartz in Carpolac and Mosquito Creek.
Other raw materials are rare. Their absence in individual smaller samples could be due to sampling factors, but the regional pattern suggests that their absence is real. The occurrence of quartzite and silcrete in Clear Lake and Natimuk is notable. These squares are the closest to $\mathrm{Mt}$ Arapiles, while Clear Lake is also close to Mt Talbot and the Black Range. Quarrying of quartzite or locally cemented sandstone has been documented in these areas (Edmonds 1992; Long 1995; Bird and Frankel 1998). Silcrete sources have been recorded in the Mallee to the north of the study area (Webb 1995) but silcrete is probably also available locally (Kamminga and Grist 2000: 110).

Closer inspection of the data suggests that the assemblage composition of the large and medium artefact occurrences accounts for much of the regional differentiation. Figure 4 shows that these large and medium occurrences include a group of sites in the western part of the study area that contain high proportions of chert and a group in the east that contain high proportions of quartz. The amalgamated data for small and very small artefact occurrences are predominantly quartz dominated and show little regional variation. This distinction between the two groups of artefact occurrence may indicate a real distinction between low density and relatively uniform traces of off-site activity and the greater diversity of activities at preferred camping places.

\section{DISCUSSION}

Archaeologists commonly assume that water was a key determinant of Aboriginal settlement patterns, although this proposition is rarely tested and may only hold true in arid or semiarid regions. This study does provide such a test and suggests that, in the south-west Wimmera, archaeological material does indeed increase in quantity relative to the distribution and permanency of water at a broad regional level. Historical sources suggest that swamps and lakes would have been significant foci of Aboriginal land use, and medium to large artefact scatters can thus be expected where suitable conditions of exposure and visibility exist. The results of the survey support this hypothesis.

Stratum 5 comprises landscape areas that do not necessarily fit this overall regional trend and needs to be considered in more detail. Stratum 5 comprises 'outliers' or sample units containing either rugged terrain or major rivers. The two stratum 5 squares actually surveyed are associated with the Wimmera River. One might expect the archaeological record in these squares to be comparable to stratum 4 and that, like lakes and swamps, the river too would be an important focus of settlement. In fact, stratum 5 assemblages proved 
more comparable to stratum 3 (rolling terrain with numerous seasonal waterways).

The differences in archaeological densities between strata 3,4 and 5 should not, however, be uncritically accepted to indicate real variation in intensity of land use. There are two possible factors - one behavioural and one related to processes of site formation - that may be influencing the observed pattern. First, the configuration of terrain may influence choice of campsite location. Choice may well be more limited close to point water sources, such as soaks, lakes and swamps, than close to linear water sources, such as rivers and creeks. A preference for camping on sandy well-drained areas close to lakes and swamps further constrains site location. There may also be a seasonal factor. The cooler locations close to bodies of water may be preferred summer camping sites. In contrast, along the banks of creeks and rivers there are no constraints on the placement of camps and there is a lower probability of repeated occupation at any one location. This in turn may result in relatively dense and diverse assemblages of archaeological material around point water sources contrasting with more dispersed and lower density occurrences along linear water sources.

Second, differential exposure characteristics may also be an important factor affecting observed site densities. Differential exposure means that what is in reality a continuous scatter of cultural material manifests itself as several apparently discontinuous occurrences of artefacts which will consequently be recorded as separate 'sites', but are in reality small 'windows' of visibility into a more extensive archaeological deposit. The preference for camping on source bordering dunes, which are relatively unstable and easily eroded, may artificially inflate the quantity and 'obtrusiveness' of archaeological material associated with lakes and swamps due to greater exposure. By contrast, contemporary land management practice is to conserve streamside reserves and consequently they are less likely to be substantially eroded. Consequently, exposure of archaeological material associated with these landforms is likely to be more limited. This illustrates the complex interaction between natural and cultural processes that creates the archaeological record that we observe today. Similarly the conservation of natural vegetation along rivers and streams tends to preserve scarred trees and thus contributes to their high representation in strata 3 and 5 .

Therefore, although large archaeologically significant sites are found today in association with point water sources, these might not necessarily be of more behavioural significance than the dispersed scatters associated with linear water sources. The importance of linear water sources to
Aboriginal people is not so much reflected in the presence of substantial concentrations of artefacts, but by a gradient in the 'background scatter' at a regional level. Even so, the two medium/large sites in Square 5A are extensive and continuous scatters of artefacts associated with linear water sources. Since this survey was completed several small shell middens have been recorded along the Wimmera River south of Dimboola at the eastern margin of the Little Desert (Russell 1992a). More recent information from Edmonds' surveys of the Wimmera River (Archaeological Consulting Services 1997; Edmonds 1998) and Kamminga and Grist's (2000) work on the Yarriambiack Creek show how these major watercourses act as foci for settlement in the semi-arid environment of the Wimmera and Mallee in western Victoria.

Rugged terrain is the other main distinguishing feature of stratum 5. It is likely therefore that stratum 5 squares containing outcrops of Grampians sandstones or Rocklands Volcanics would also be anomalous in terms of the regional trend. These types of locations may contain rock shelters or quarry sites in addition to or instead of scarred trees and artefact scatters. Since this survey was completed, some further surveys have been conducted in the study area. The Mt ArapilesTooan survey and subsequent management and monitoring reports (Edmonds 1992; Long 1995a, 1995b) documented substantial evidence of quartzite quarrying, in some cases associated with small rock shelters. Rock art has also been recorded at Mt Arapiles. Therefore, the prediction that the distinctive landscape features characteristic of stratum 5 will generate correspondingly distinctive archaeological evidence is supported.

\section{CONCLUSIONS}

From a regional archaeological perspective, artefact assemblages are generally uniform throughout the study area. There is no evidence for substantial technological variation in the southwest Wimmera, except for some variation in raw materials from west to east. This tends to suggest that the varying density noted in the analysis of site distribution genuinely reflects Aboriginal land use patterns and is not a product of differences in technology or access to raw materials.

At a local level, artefact sites occur in association with a range of environments. However, they are rarest in sand plain areas carrying brown stringybark woodlands and commonest on lakeshores and source bordering dunes. Sites are also relatively common on alluvial plains supporting a mosaic of red gum forest and gum/box/buloke savannah woodland. Brown stringybark woodlands are the least productive environments in the study area so it is not 
surprising that they are not rich in sites.

At a regional level, this study shows that the distribution and characteristics of Aboriginal archaeological sites in the south-west Wimmera are strongly linked to the distribution and nature of water sources. The evidence of past Aboriginal activity is more abundant in areas where surface water is both abundant and reliable. Within this general distribution, certain landscape features seem to act locally as 'hotspots', or foci of past Aboriginal settlement. In the south-west Wimmera, permanent lakes and swamps are the most prominent 'hotspots' and sample squares with these features proved to have the greatest densities of archaeological material. This undoubtedly reflects the high productivity of these locations and confirms the observation from historic sources that lakes and swamps, and their associated resources, were important foci of Aboriginal settlement (e.g. Mitchell 1838; Bride 1898; Carter 1911; Morris 1943; Robinson 8-9 July 1841, in Presland 1980: 91-92; Hamilton 1981; Gott 1982). Elsewhere in the Wimmera, large concentrations of archaeological material are associated with prominent wetlands such as Dooen Swamp (Gunn 1997), Blackfellows Waterhole (McConnell 1985) and Lake Lonsdale (Russell 1992b; Kelton 1995), particularly where source bordering dunes have eroded. Riverine areas, especially the Wimmera River, are also important, although the linear character of associated settlement and the reduced exposure of artefact material where native vegetation has been maintained means that the archaeological signature may not be as prominent as for wetlands.

From a methodological perspective, the stratified sampling strategy used in this study is an unusual one. Instead of using land systems derived from soils, geomorphology and vegetation, the region was analysed using a set of mapped landscape attributes relating to variation in relief, water sources and other specific features. The results suggest that this methodology has predictive power at a regional level and thus has considerable value as a tool for managers of Aboriginal cultural heritage.

\section{ACKNOWLEDGMENTS}

Members of the Goolum Goolum Aboriginal Co-operative, and staff of the former Victoria Archaeological Survey and the Horsham regional office of the former Department of Conservation and Environment all provided support for the field program. Staff at Aboriginal Affairs Victoria provided support for the writing of the original report. Nicola Stern made helpful comments on a draft of this paper.

\section{REFERENCES}

Anderson, J. (1984). Between plateau and plain: flexible responses to varied environments in southwestern Australia. Occasional Papers in Prehistory 4. Department of Prehistory, Research School of Pacific Studies, Australian National University: Canberra.

Archaeological Consulting Services. (1997). The Wimmera River Cultural Heritage Study Stage 1: the Upper Wimmera Basin. Unpublished report to the Goolum Goolum Aboriginal Co-operative: Horsham, Australia.

Bird, C.F.M. (1985). Prehistoric lithic resource utilisation. PhD thesis, University of Western Australia: Nedlands.

Bird, C.F.M. (1990). Aboriginal sites in the Horsham Region. Unpublished report for the Victoria Archaeological Survey, Melbourne.

Bird, C.F.M. (1995). Mount Talbot 1: a rockshelter in the southern Wimmera, Victoria, Australia. The Artefact 18: $12-21$.

Bird, C.F.M. and Frankel, D. (1998). Pleistocene and Early Holocene archaeology in Victoria: a view from Gariwerd. The Artefact 21: 48-62.

Bird, C.F.M., Frankel, D. and Van Waarden, N. (1998). New radiocarbon determinations from the Grampians-Gariwerd region. Archaeology in Oceania 33: 31-36.

Bird, C.F.M. and Frankel, D. (2005). An archaeology of Gariwerd: from Pleistocene to Holocene in Western Victoria. Tempus 8. Anthropology Museum, University of Queensland: St Lucia.

Bowler, J.M. and Magee, J.W. (1978). Geomorphology of the Mallee region in semi-arid northern Victoria and western New South Wales. Proceedings of the Royal Society of Victoria 90: 5-26.

Bride, T.F. (1898). Letters from Victorian pioneers. Government Printer: Melbourne.

Brown, S.H. (1987). Towards a prehistory of the Hamersley Plateau, Northwest Australia. Occasional Papers in Prehistory 6. Department of Prehistory, Research School of Pacific Studies, Australian National University: Canberra.

Carter, S. (1911). Reminiscences of the early days in the Wimmera. Norman Brothers: Melbourne.

Cayley, R.A. and Taylor, D.H. (1997). Grampians. Geological Survey Report No. 107.

Clark, I.D. (1990) Aboriginal languages and clans: an historical atlas of western and central Victoria, 1800-1900. Monash Publications in Geography No. 37. Department of Geography and Environmental Science, Monash University: Melbourne.

Clark, I.D. (1998). 'That's my country, belonging to me': Aboriginal land tenure and dispossession in nineteenth century western Victoria. Heritage Matters: Melbourne.

Coutts, P.J.F. and Lorblanchet, M. (1982). Aboriginals and rock art in the Grampians, Victoria, Australia. Records of the Victorian Archaeological Survey 12.

Coutts, P.J.F. and Witter, D.C. (1977). New radiocarbon dates for Victorian archaeological sites. Records of the Victorian Archaeological Survey 4: 59-73.

Coutts, P.J.F., Witter, D.C., McIlwraith, M. and Frank, R. (1976). The mound people of Western Victoria: a preliminary statement. Records of the Victorian 
Archaeological Survey 1.

Doelman, T. (2005). Quarrying masses of information: an approach to the recording and interpretation of a quarry assemblage. Archaeology in Oceania 40: 50-61.

Doelman, T., Webb, J. and Domanski, M. (2001). Source to discard: patterns of lithic raw material procurement and use in Sturt National Park, northwestern New South Wales. Archaeology in Oceania 36: 15-33.

Dunnell, R.C. and Dancey, W.S. (1983). The siteless survey: a regional scale data collection strategy. Advances in Archaeological Method and Theory 6: 267287.

Ebert, J. (1992). Distributional archaeology. University of New Mexico Press: Albuquerque.

Edmonds, V. (1992). Mt Arapiles-Tooan State Park archaeological survey. Unpublished report to the Goolum Goolum Aboriginal Co-operative: Horsham, Australia.

Edmonds, V. (1998). The Wimmera River Cultural Heritage Study. Stage II. The Middle Wimmera Basin. Unpublished report to the Goolum Goolum Aboriginal Cooperative: Horsham, Australia.

Ferguson, W.F. (1985). A mid-Holocene depopulation of the Australian south-west. PhD thesis, Australian National University: Canberra.

Foley, R. (1981). Off-site archaeology: an alternative approach for the short-sited (pp. 157-183). In: Hodder, I., Isaac, G.L. and Hammond, N. (eds), Pattern of the past: studies in honour of David Clarke. Cambridge University Press: Cambridge.

Gott, B. (1982). Ecology of root use by the Aborigines of southern Australia. Archaeology in Oceania 17: 59-67.

Gunn, R.G. (1983). Aboriginal rock art in the Grampians. Records of the Victorian Archaeological Survey No. 16.

Gunn, R.G. (1987). Black Range 2 (Site 7323/023) and the art of the Black Range, western Grampians. Unpublished report for the Victoria Archaeological Survey: Melbourne.

Gunn, R.G. (1997). Dooen Swamp sand-dune portion: Aboriginal sites survey. Unpublished report to Barry Hutchinson (Extractive Industries Consultant) and G.W. Brain: Horsham, Australia.

Hallam, S.J. (1977). Topographic archaeology and artefactual evidence (pp. 169-177). In: Wright, R.V.S. (ed.), Stone tools as cultural markers: change, evolution and complexity. Australian Institute of Aboriginal Studies: Canberra.

Hallam, S.J. (1987). Coastal does not equal littoral. Australian Archaeology 25: 10-29.

Hamilton, J.C. (1981). Pioneering days in Western Victoria (Facsimile edition). Warrnambool Institute Press: Warrnambool.

Haselgrove, C., Millett, M. and Smith, I. (eds) (1985). Archaeology from the ploughsoil: studies in the collection and interpretation of field survey data. Department of Archaeology and Prehistory, University of Sheffield: Sheffield.

Holdaway, S.J., Witter, D., Fanning, P., Musgrave, R., Cochrane, G., Doelman, T., Greenwood, S., Pigdon, D. and Reeves, J. (1998). New approaches to open site spatial archaeology in Sturt National Park, New South
Wales, Australia. Archaeology in Oceania 33: 1-19.

Holdaway, S., Fanning, P. and Shiner, J. (2005). Absence of evidence or evidence of absence? Understanding the chronology of Indigenous occupation of western New South Wales, Australia. Archaeology in Oceania 40: 33-49.

Hughes, P. and Sullivan, M. (1984). Environmental approaches to assessing archaeological significance (pp. 34-47). In: Sullivan, S. and Bowdler, S. (eds), Site surveys and significance assessment in Australia. Department of Prehistory, Research School of Pacific Studies, Australian National University: Canberra.

Jenkin, J.J., Lawrence, C.R., Kenley, P.R., Gill, E.D., Macumber, P.G. and Neilson, J.L. (1988). Quaternary (pp. 351-402). In: Douglas, J.G. and Ferguson, J.A. (eds), Geology of Victoria. Geological Society of Australia. Victorian Division: Melbourne.

Kamminga, J. and Grist, M. (2000). Yarriambiack Creek Aboriginal Heritage Study. Unpublished report to Aboriginal Affairs Victoria: Melbourne.

Kelton, J. (1995). An archaeological survey and heritage assessment: Lake Lonsdale recreation area, near Stawell and Halls Gap, western Victoria. Unpublished report to Wimmera Mallee Water, Brambuk Incorporated and Heritage Services Branch, Aboriginal Affairs Victoria: Melbourne.

Land Conservation Council. (1979). Report on the Southwestern Area, District 2. Land Conservation Council: Melbourne.

Land Conservation Council. (1985). Report on the Wimmera Area. Land Conservation Council: Melbourne.

Long, A.T. (1995a). Detailed recording and sample surface collections at the Bluffs Quarry 1 (AAV Site No. 7224199), Mt Arapiles. Unpublished report for Aboriginal Affairs Victoria: Melbourne.

Long, A. (1995b). Aboriginal site management study: Mt Arapiles-Tooan State Park. Unpublished report for Aboriginal Affairs Victoria: Melbourne.

Lourandos, H. (1980). Change or stability? Hydraulics, hunter-gatherers and population in temperate Australia. World Archaeology 11: 245-264.

Massola, A. (1962). The native fish traps at Toolondo in the Wimmera. Victorian Naturalist 79: 162-163.

McBryde, I. (1978). Wil-im-ee Mooring: or, where do axes come from? Mankind 11: 354-382.

McBryde, I. (1986). Australia's once and future archaeology. Archaeology in Oceania 21: 13-28

McConnell, A. (1985). Archaeological site investigation, Blackfellows Waterhole, Barrabool State Forest, Western Victoria. Unpublished report for the Victoria Archaeological Survey: Melbourne.

Mitchell, T.L. (1838). Journal of three expeditions into the interior of eastern Australia: with a description of the recently explored region of Australia Felix and of the present colony of New South Wales (Facsimile edition). Libraries of South Australia: Adelaide.

Morris, P.F. (1943). Vegetable foods in the Wimmera and Mallee. Victorian Naturalist 59: 167-170.

Pearson, M. and Sullivan, S. (1995). Looking after heritage places: the basics of heritage planning for managers, landowners and administrators. Melbourne University Press: Melbourne. 
Presland, G. (ed.) (1980). Journals of G.A. Robinson, May to August 1841. Records of the Victorian Archaeological Survey 11.

Rhoads, J.W. (1992). Significant sites and non-site archaeology: a case study from south-east Australia. World Archaeology 24: 198-217.

Rhoads, J.W. and Bird, C.F.M. (2000). An archaeological survey of the south-west Wimmera. Unpublished report to Aboriginal Affairs Victoria: Melbourne.

Ross, A. (1986). Aboriginal land use in the Mallee district of northwestern Victoria. Unpublished report for the Land Conservation Council: Melbourne.

Rossignol, J. and Wandsnider, L. (eds) (1992). Space, time and archaeological landscapes. Plenum Press: New York.

Russell, L.W. (1992a). An archaeological survey of the Wimmera River in the Wail State Forest and Little Desert National Park. Unpublished report for the Victoria Archaeological Survey and the Goolum Goolum Aboriginal Co-operative, Horsham: Australia.

Russell, L.W. (1992b). An archaeological survey of Lake Lonsdale. Unpublished report to Brambuk Inc: Halls Gap, Australia.

Schwede, M.L. (1990). Quartz, the multifaceted stone: a regional prehistory of the Helena River valley on the Swan Coastal Plain of southwestern Australia. PhD thesis, University of Western Australia: Nedlands.

Shennan, S. (1985). Experiments in the collection and analysis of archaeological survey data: the east Hampshire survey. Department of Archaeology and Prehistory, University of Sheffield: Sheffield.

Smith, M.V. (1993). Recherche à l'Esperance: a prehistory of the Esperance region of south-western Australia. PhD thesis, University of Western Australia: Nedlands.

Scott-Virtue, L. (1982). Flint: the foundation for an hypothesis. B.A. (Honours) thesis, Division of Prehistory, La Trobe University: Bundoora.

Thomas, D.H. (1975). Nonsite sampling in archaeology: up the creek without a site? (pp. 61-81). In: Mueller, J.W. (ed.), Sampling in archaeology. University of Arizona Press: Tucson.

Webb, C. (1995). The identification and documentation of silcrete quarries. Unpublished report for the Victoria Archaeological Survey: Melbourne.

MANUSCRIPT RECEIVED: NOVEMBER 2006; ACCEPTED APRIL 2007. 